\title{
Marine Pseudomonas putida: a potential source of antimicrobial substances against antibiotic-resistant bacteria
}

\author{
Palloma Rodrigues Marinho', Ana Paula Barbosa Moreira', Flávia Lúcia Piffano Costa Pellegrino", \\ Guilherme Muricy², Maria do Carmo de Freire Bastos', Kátia Regina Netto dos Santos', \\ Marcia Giambiagi-deMarval', Marinella Silva Laport ${ }^{1}{ }^{1+}$ \\ ${ }^{2}$ Departamento de Invertebrados, Museu Nacional ${ }^{1}$ Departamento de Microbiologia Médica, \\ Instituto de Microbiologia Prof. Paulo de Góes, Centro de Ciências da Saúde, Universidade Federal do Rio de Janeiro, \\ Av. Carlos Chagas Filho 373, 21941-590 Rio de Janeiro, RJ, Brasil
}

Bacteria isolated from marine sponges found off the coast of Rio de Janeiro, Brazil, were screened for the production of antimicrobial substances. We report a new Pseudomonas putida strain (designated P. putida Mm3) isolated from the sponge Mycale microsigmatosa that produces a powerful antimicrobial substance active against multidrug-resistant bacteria. P. putida Mm3 was identified on the basis of $16 S \mathrm{SRNA}$ gene sequencing and phenotypic tests. Molecular typing for Mm3 was performed by RAPD-PCR and comparison of the results to other Pseudomonas strains. Our results contribute to the search for new antimicrobial agents, an important strategy for developing alternative therapies to treat infections caused by multidrug-resistant bacteria.

Key words: antimicrobial substance - Pseudomonas putida - sponge-associated bacteria

The increasing prevalence of multidrug-resistant bacteria has made the search for new antimicrobial agents an important strategy in the establishment of alternative therapies for difficult-to-manage infections (Rice 2006). Microorganisms produce many of the natural products isolated from marine invertebrate sources. The extensive association between marine invertebrate species and marine microbiota is remarkable. For instance, bacteria can constitute up to $40 \%$ of the total weight of some sponges. Sponges and other marine invertebrates harbour diverse microorganisms and benefit from the rich source of chemicals produced by microbes, which can protect these sponges or other hosts against predators or pathogens (Gerwick et al. 2008).

The large number of strains recovered with antimicrobial activity suggests that marine sponges represent an ecological niche harbouring a largely uncharacterised microbial diversity and as yet unexploited potential in the search for new secondary metabolites. This offers the possibility of using sponge-associated bacteria instead of the sponge itself for the production of biologically active substances. Since bacteria rapidly produce large quantities of biomass, biologically active products can be easily obtained on a biotechnological scale without the need for cultivating or harvesting the sponges. In many instances, the limited availability of sponge material may preclude the commercial production of bioactive compounds (Müller et al. 2004).

Financial support: FUJB - ALV 2005 (APM), FAPERJ (MSL, GM), CNPq/PIBIC (PRM, GM), PETROBRÁS (GM)

+ Corresponding author: marinella@micro.ufrj.br

Received 1 September 2008

Accepted 25 May 2009
The marine sponges Mycale microsigmatosa, Petromica citrina and Polymastia janeirensis are abundant species in Cagarras Archipelago, Rio de Janeiro, Southeastern Brazil (Monteiro \& Muricy 2004). However, very little is known about the antimicrobial activity of sponges from the Rio de Janeiro coast. As the study of marine sponge-associated bacteria and their potential role in the production of pharmacologically active metabolites is a promising new topic for research, in the present study we isolated and characterised bacteria with antimicrobial activities from marine sponges.

\section{MATERIALS AND METHODS}

Samples of the sponges $M$. microsigmatosa, $P$. citrina and $P$. janeirensis were collected by SCUBA diving at depths of 4-20 $\mathrm{m}$ at Praia Vermelha beach $\left(22^{\circ} 57^{\prime} \mathrm{S}\right.$ $\left.43^{\circ} 09^{\prime} \mathrm{W}\right)$ and Cagarras Archipelago (23ำ $\left.01^{\prime} \mathrm{S} 43^{\circ} 11^{\prime} \mathrm{W}\right)$ in Rio de Janeiro. After collection, specimens were processed under aseptic conditions as follows: macroorganisms were removed from the fresh material and the specimens were weighed; sponges were macerated in brain heart infusion medium (BHI - Difco - Detroit, Michigan, USA), Marine medium (Marine 2216 - Difco) dissolved in sterile water and Marine medium dissolved in seawater at a final concentration of about $1 \mathrm{~g} / \mathrm{mL}$. Macerates of each sponge were inoculated in replicates on BHI-agar, Marine-agar and Marine/seawater-agar and incubated up to seven days at RT $\left(25-30^{\circ} \mathrm{C}\right)$. Bacterial cultures were examined daily for growth and colony morphology. Then, the bacteria were purified from the culture and kept in slant cultures at $-20^{\circ} \mathrm{C}$. Bacteria used as indicator strains in the assay for production of antimicrobial substances were: Corynebacterium fimi NCTC 7547, Staphylococcus aureus ATCC 29213, Staphylococcus epidermidis ATCC 12228, Escherichia coli ATCC 25922, Pseudomonas aeruginosa ATCC 27853 and Enterobacter cloacae ATCC 25355 and the drug- 
resistant clinical strains Enterococcus faecalis V583 (resistant to vancomycin, erythromycin, chloramphenicol and kanamycin), S. aureus 42AE (resistant to methicillin - MRSA), S. epidermidis 57s (resistant to penicillin, ampicillin, ciprofloxacin and tetracycline), E. coli $54 \mathrm{AE}$ (resistant to ampicillin, tetracycline, trimethoprim/sulphamethoxazol and chloramphenicol), E. cloacae $43 \mathrm{AE}$ (resistant to cephalothin, ampicillin, cefoxitin and tetracycline), $P$. aeruginosa $2 \mathrm{AE}$ (resistant to aztreonam and piperacillin/tazobactam). These strains were grown in BHI medium at $37^{\circ} \mathrm{C}$ for $18 \mathrm{~h}$. Four clinical strains (three Pseudomonas putida and one Pseudomonas fluorescens) were used as a comparison group for RAPD-PCR analysis. Pseudomonas strains were grown for $18 \mathrm{~h}$ at $37^{\circ} \mathrm{C}$ on Trypticase Soy Broth (TSB, Difco).

The assay for antimicrobial substance production was performed in triplicate as described previously by Giambiagi-deMarval et al. (1990). Briefly, $10^{7}$ cells of the marine strains were spotted onto BHI-agar, marineagar or marine/seawater-agar. After growth of each marine strain at $\mathrm{RT}$ or $37^{\circ} \mathrm{C}, 10^{5}$ cells of the indicator strains (Table) in $3 \mathrm{~mL}$ of BHI soft agar were poured over the plates. When reference or drug-resistant clinical strains were used as indicator strains, the plates were incubated at $37^{\circ} \mathrm{C}$ for $18 \mathrm{~h}$; when marine strains were used as indicators, the plates were incubated at RT for up to seven days. The inhibition zones formed around the spots of strains that produce antimicrobial substances were ob- served. An indicator strain was considered sensitive to the activity of a given marine strain when it exhibited a clear inhibition zone with a diameter $\geq 8 \mathrm{~mm}$. When the inhibition zone was $<8 \mathrm{~mm}$ or when bacterial colonies grew inside the inhibition zone, the indicator strain was considered resistant. The effects of trypsin (Sigma - St. Louis, Mo, USA), proteinase K (Sigma), protease XXIII (Sigma) and $0.2 \mathrm{~N} \mathrm{NaOH}$ on the activity of the antimicrobial substance produced by marine strains on BHI-agar were determined by the method described by Giambiagi-deMarval et al. (1990). In all assays that used C. fimi NCTC 7547 as the indicator strain, the lack of inhibition zones suggested that the antimicrobial substance had either a proteinaceous or an acidic nature.

Marine strains with antimicrobial activity were characterised using morphological and biochemical tests according to standard methods, i.e., the catalase test (3\% $\mathrm{H}_{2} \mathrm{O}_{2}$ ), oxidase test, glucose, sucrose and lactose fermentation (Atlas et al. 1995). Production of antimicrobial substances was assayed at either $37^{\circ} \mathrm{C}$ or RT. Cell morphology and Gram staining were observed using light microscopy. The antibiotic sensitivity profile was determined by the disk diffusion method, according to the CLSI (2003) with modifications. The following antibiotics (sensibiodiskCECON - Centro de Controle e Produtos para Diagnóstico LTDA - São Paulo, Brazil) were used: Amikacin (30 $\mu \mathrm{g})$, Aztreonam $(30 \mu \mathrm{g})$, Cefepime $(30 \mu \mathrm{g})$, Ceftazidime $(30 \mu \mathrm{g})$, Chloramphenicol $(30 \mu \mathrm{g})$, Ciprofloxacin $(5 \mu \mathrm{g})$,

TABLE

Bacterial strains from marine sponges presenting antimicrobial activity when grown at RT

\begin{tabular}{|c|c|c|c|c|c|c|c|}
\hline \multirow[b]{2}{*}{ Indicator bacteria } & \multicolumn{7}{|c|}{ Marine strains with antimicrobial activity (inhibition zone in $\mathrm{mm}$ ) } \\
\hline & Pc1 & $\mathrm{Pj} 1$ & $\mathrm{Pj} 2$ & $\mathrm{Pj} 3$ & Mm1 & $\mathrm{Mm} 2$ & $\mathrm{Mm} 3$ \\
\hline \multicolumn{8}{|l|}{ Reference strains } \\
\hline Corynebacterium fimi NCTC 7547 & $19^{a}$ & 18 & 19 & 19 & 20 & 20 & 21 \\
\hline Staphylococcus aureus ATCC 29213 & $-{ }^{b}$ & - & - & - & - & - & 17 \\
\hline Staphylococcus epidermidis ATCC 12228 & - & - & - & - & - & - & 18 \\
\hline Escherichia coli ATCC 25922 & - & - & - & - & - & - & 14 \\
\hline Escherichia coli ATCC 27853 & - & - & - & - & - & - & 15 \\
\hline Enterobacter cloacae ATCC 25355 & - & - & - & - & - & - & 16 \\
\hline \multicolumn{8}{|l|}{ Drug-resistant strains } \\
\hline Staphylococcus aureus $42 \mathrm{AE}$ & - & - & - & - & - & - & - \\
\hline Staphylococcus epidermidis 57AE & - & - & - & - & - & - & 11 \\
\hline Enterococcus faecalis V583 & - & - & - & - & - & - & - \\
\hline Escherichia coli $54 \mathrm{AE}$ & - & - & - & - & - & - & 10 \\
\hline Escherichia coli $2 \mathrm{AE}$ & - & - & - & - & - & - & 12 \\
\hline Enterobacter cloacae 43AE & - & - & - & - & - & - & 12 \\
\hline \multicolumn{8}{|l|}{ Marine strains } \\
\hline Pc1 & - & - & - & - & - & - & 11 \\
\hline $\mathrm{Pj} 1$ & - & - & - & - & - & - & 10 \\
\hline $\mathrm{Pj} 2$ & - & - & - & - & - & - & 11 \\
\hline $\mathrm{Pj} 3$ & - & - & - & - & - & - & 10 \\
\hline $\mathrm{Mm} 1$ & - & - & - & - & - & - & 9 \\
\hline $\mathrm{Mm} 2$ & - & - & - & - & - & - & 9 \\
\hline $\mathrm{Mm} 3$ & - & - & - & - & - & - & - \\
\hline
\end{tabular}

$a$ : average of three measures of the diameter of inhibition zone; $b$ : absence of inhibition zone. Only the bacterial strains from sponges $[P$. citrina $(\mathrm{Pc})$, P. janeirensis $(\mathrm{Pj})$ and M. microsigmatosa $(\mathrm{Mm})]$ that inhibited at least one indicator strain are shown. 
Imipenem $(10 \mu \mathrm{g})$, Meropenem $(10 \mu \mathrm{g})$, Piperacillin/tazobactam $(110 \mu \mathrm{g})$, Trimethoprim/sulphamethoxazol (1.25$23.75 \mu \mathrm{g})$ and Tetracycline $(30 \mu \mathrm{g})$. The diameters of the inhibition zones were interpreted according to the CLSI guidelines (2003) after the growth at RT during an incubation time specific for each strain.

The Mm3 strain was identified using the Vitek automated system with the GNI card (bioMérieux Vitek Inc - Hazelwood, Mo, USA), API 20NE (bioMéuriex) and conventional biochemical tests (Blondel-Hill et al. 2007): pigment production, glucose oxidation, arginine dihydrolase and lysine decarboxylase activities, growth at $42^{\circ} \mathrm{C}$, motility, gelatinase production test, nitrate reduction and production of acid from xylose. Metallobeta-lactamase production was also investigated for this strain by a disk approximation test using 2-mercaptopropionic acid as inhibitor as previously described (Arakawa et al. 2000).

Strains showing antimicrobial activity were selected for molecular identification by 16S rRNA partial sequencing. Total DNA was extracted from stationary phase cultures using standard phenol-chloroform extraction procedures (Sambrook et al. 2001). PCR amplification was performed with universal primers (f: 5'-GATTAGATACCCTGGTAGTCCAC-3' and r: 5'CCCGGGAACGTATTCACCG-3') specific for the 16S rRNA gene (Siqueira et al. 2002). The reaction was carried out in a total volume of $50 \mu \mathrm{L}$ containing $100 \mathrm{ng}$ of DNA, $4 \mathrm{mM} \mathrm{MgCl}$, 1 x PCR reaction buffer (Ultratools DNA Polymerase, Biotools - Madrid, Spain), $2.5 \mathrm{mM}$ of each deoxyribonucleotide triphosphate, $1.5 \mathrm{U}$ of Taq polymerase (Ultratools DNA Polymerase, Biotools) and $40 \mathrm{pmol}$ of each primer. Cycle conditions were: initial denaturation $\left(2 \mathrm{~min}\right.$ at $\left.95^{\circ} \mathrm{C}\right)$, followed by 36 cycles of denaturation $\left(30 \mathrm{~s}\right.$ at $\left.95^{\circ} \mathrm{C}\right)$, primer annealing $(1 \mathrm{~min}$ at $\left.60^{\circ} \mathrm{C}\right)$ and primer extension $\left(1 \mathrm{~min}\right.$ at $\left.72^{\circ} \mathrm{C}\right)$ and a final primer extension step $\left(2 \mathrm{~min}\right.$ at $\left.72^{\circ} \mathrm{C}\right)$. Amplification was performed on a Programmable Thermal Controller (PTC-100TM, MJ Research, USA).

Amplicons were analysed in $1 \%(\mathrm{w} / \mathrm{v})$ agarose gels. The gels were stained in an aqueous solution containing ethidium bromide $(0.5 \mathrm{mg} / \mathrm{mL})$ and visualised on a UV transilluminator. Amplicons were purified using the QIAquick purification kit (QIAGEN, Inc. - Valencia, Ca, USA) and sequenced. The sequencing was performed on an ABI PRISM 310 Genetic Analyser (Perkin-Elmer Applied Biosystems - Foster City, USA) using the universal primers (described for PCR amplification) and the Big Dye Terminator Cycle Sequencing Ready Reaction Kit (Perkin Elmer Applied Biosystems).

The partial 16S rRNA gene sequences obtained were aligned using ABI Prism software (Perkin Elmer Applied Biosystems) and compared to sequences retrieved by the queries generated by BLAST of GenBank Database. Phylogenetic analysis was performed with the MEGA 4.0 program (Molecular Evolutionary Genetics Analysis, Version 4.0) (Tamura et al. 2007). The tree topologies were evaluated by bootstrap analyses based on 1,000 replicates (Felsenstein 1985) and phylogenetic trees were inferred using the neighbour-joining method
(Saitou \& Nei 1987). RAPD-PCR typing was performed with primer 272 (Mahenthiralingam et al. 1996) for the Mm3 strain and four clinical Pseudomonas strains, used as a comparison group. Total DNA was obtained from stationary phase cultures by boiling lysis. PCR was carried out in a total volume of $25 \mu \mathrm{L}$ containing $1.5 \mathrm{mM}$ $\mathrm{MgCl}_{2}, 1$ x PCR reaction buffer, $2.5 \mathrm{mM}$ of each deoxyribonucleotide triphosphate, $1 \mathrm{U}$ of Taq-polymerase and $2.5 \mathrm{pmol}$ of primer and $3 \mu \mathrm{L}$ of DNA (Pellegrino et al. 2006). PCR fingerprints were analysed in $1.5 \%(\mathrm{w} / \mathrm{v})$ agarose gel, stained with ethidium bromide, visualised on a UV transilluminator and photographed. Banding patterns were interpreted by visual inspection and by using the GelCompar II program, version 4.01 (Applied Maths - Kortrijk, Belgium) employing the Dice index and the unweighted pair group method with arithmetic averages (UPGMA). Mm3 plasmid DNA was extracted by alkaline lysis (Giambiagi-deMarval et al. 1990) and analysed in $1 \%(\mathrm{w} / \mathrm{v})$ agarose gels. Plasmid size was determined by comparison to plasmid standards from $E$. coli V517 (NCTC 50193) and E. coli 39R861 (NCTC 50192) strains.

\section{RESULTS AND DISCUSSION}

Accumulating evidence has shown that bacteria associated with sponges represent the real origin of many antimicrobial substances of interest (Faulkner et al. 2000). Therefore, we screened homogenisates of the sponges $M$. microsigmatosa, P. citrina and P. janeirensis. A total of 32 bacterial strains were isolated: 10 on BHI-agar, 11 on Marine-agar and 11 on Marine/seawater-agar. The three cultivation conditions showed no significant differences regarding the number of recovered strains, colony morphology or size. All 32 strains were assayed for antimicrobial activity against indicator bacteria. Seven strains isolated on BHI-agar inhibited at least one indicator strain (Table). No antimicrobial activity was observed from isolates cultivated on Marine-agar and Marine/ seawater-agar. These data suggest that the growth medium may influence antimicrobial substance production, as reported by Nascimento et al. (2004). Interestingly, the seven strains showed antimicrobial activity only when grown at RT, while no antimicrobial activity was detected at $37^{\circ} \mathrm{C}$. This suggests that temperature can also influence the capacity of the bacteria to produce antimicrobial substances. These strains could play a role in the microbial community dynamics of the external microflora of M. microsigmatosa, P. citrina and P. janeirensis sponges by limiting their densities. One of these strains, obtained from the sponge M. microsigmatosa and referred to as $\mathrm{Mm} 3$, exhibited a wide range of antimicrobial activities against reference and drug-resistant clinical strains (Table). When seven marine strains were tested for cross-inhibition, only Mm3 inhibited all other strains except itself (Table). This result suggested that the antimicrobial substance produced by $\mathrm{Mm} 3$ strain could be of a different class than the antimicrobial substances synthesised by the other marine strains assayed. We analysed the effects of proteolytic enzymes and 0.2 $\mathrm{N} \mathrm{NaOH}$ on the antimicrobial substance produced by the Mm3 strain. These results demonstrated that the anti- 
microbial substance was resistant to $0.2 \mathrm{~N} \mathrm{NaOH}$, discounting the possibility that the inhibition exhibited was due to organic acids produced by Mm3 during its metabolism. The antimicrobial substance was also resistant to all proteolytic enzymes tested, suggesting that its structure does not contain a biologically active proteinaceous component. However, the proteinaceous nature of the antimicrobial substance cannot be completely ruled out, since some bacteria produce protease-resistant peptides with antimicrobial activity, for example, Aureocin A53 produced by S. aureus strain A53 (Netz et al. 2002).

The morphological characteristics of the seven strains with antimicrobial activity showed that colonies were pigmented (white, cream, yellow or red) and Gram staining indicated that the strains were Gram-negative bacteria, forming short rods. Biochemical characterisation showed that all strains were catalase and oxidase-positive and non-fermenters for sugars such as glucose, sucrose or lactose. Six strains, two isolated from M. microsigmatosa $(\mathrm{Mm} 1$ and $\mathrm{Mm} 2)$, one from P. citrina $(\mathrm{Pc1})$ and three from $P$. janeirensis $(\mathrm{Pj} 1, \mathrm{Pj} 2$ and $\mathrm{Pj} 3)$ grew in four days at RT or at $37^{\circ} \mathrm{C}$. These strains were highly sensitive

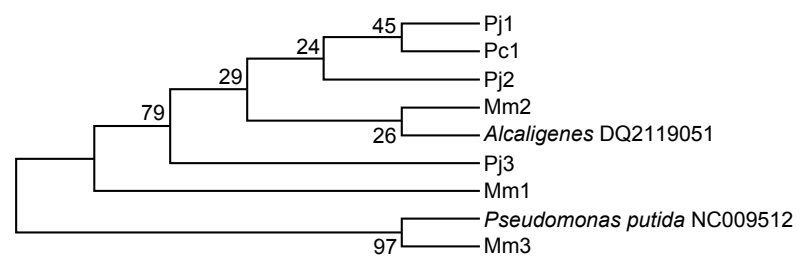

Fig. 1: neighbor-joining phylogenetic tree from analysis based on partial 16S rRNA gene sequences showing the relationship of the marine strains isolated from Polymastia janeirensis ( $\mathrm{Pj} 1, \mathrm{Pj} 2$ and $\mathrm{Pj} 3$ ), Mycale microsigmatosa ( $\mathrm{Mm} 1$ and $\mathrm{Mm} 2)$ and Petromica citrina $(\mathrm{Pc} 1)$ to the genus Alcaligenes (GenBank DQ211905.1) and the marine strain Mm3 to Pseudomonas putida (GenBank NC00951.2). Percentage bootstrap values with 1,000 resamplings are indicated at nodes. to ciprofloxacin, imipenem, meropenem and amikacin. Aztreonam resistance was observed in all strains. As the phenotypic characteristics were very similar for all six isolates, they were considered likely to be closely related. Molecular identification by partial 16S rRNA gene sequencing revealed that strains $\mathrm{Pj} 1, \mathrm{Pj} 2$ and $\mathrm{Pj} 3, \mathrm{Mm} 1$ and $\mathrm{Mm} 2$ and $\mathrm{Pc} 1$ were all related (with percentages of similarity ranging from 94-98\%) to the genus Alcaligenes (GenBank DQ211905.1), belonging to the group Betaproteobacteria. Our results confirm data published by other authors that demonstrated that Alcaligenes is a common sponge-associated bacterial genus able to inhibit bacterial growth in vitro (Olson et al. 2002).

Only the Mm3 strain showed distinct phenotypic characteristics. This strain was stained as a Gram-negative rod, is a non-fermenter for sugars, grew overnight at either RT or $37^{\circ} \mathrm{C}$ and produced a yellow-green fluorescent pigment which is highly water-soluble. Mm3 is resistant to aztreonam, chloramphenicol and trimethoprim/ sulphamethoxazol. The partial sequence analysis of the 16S rRNA gene showed a high percentage of similarity (98\%) to the corresponding sequences of the species $P$. putida (GenBank NC00951.2). A phylogenetic analysis based on partial 16S rRNA gene sequences was carried out on the seven marine strains, aligned together with one Alcaligenes sp. strain and one P. putida strain (Fig. 1).

An important observation of this study was that Mm3 strain exhibited a wide range of antimicrobial activity against reference strains and drug-resistant clinical isolates. Therefore, we performed additional tests to identify $\mathrm{Mm} 3$ at the species level. The Vitek system identified this strain as P. fluorescens/putida (94\%), demonstrating that Vitek was unable to identify this environmental bacterium to the species level. By API 20NE, the Mm3 strain showed an $84.8 \%$ similarity with the species $P$. putida. With the exception of growth at $42^{\circ} \mathrm{C}$, all biochemical tests used confirmed this strain as P. putida (BlondelHill et al. 2007). Although the strain could grow at $42^{\circ} \mathrm{C}$,

A

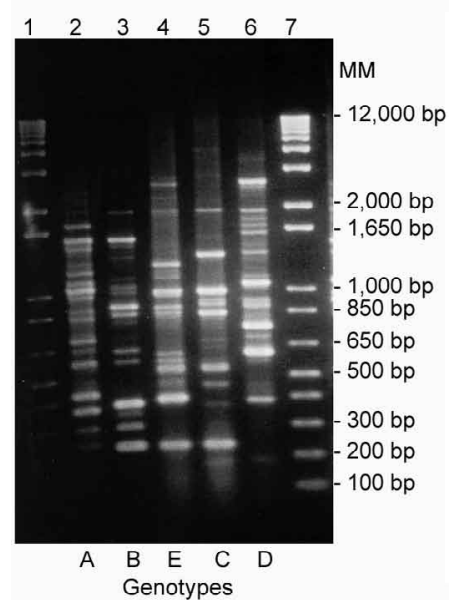

B

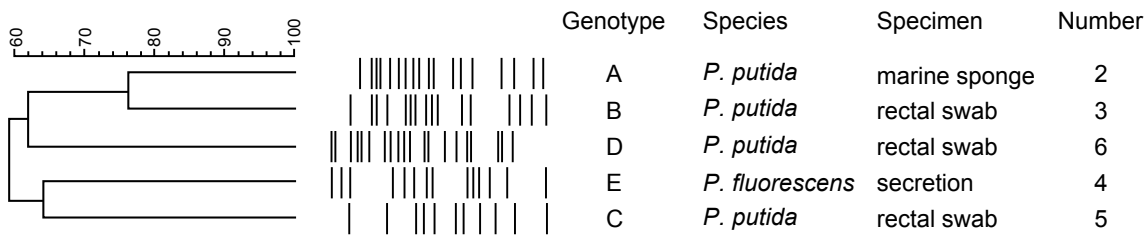

Fig. 2: A: RAPD-PCR typing of Pseudomonas putida and Pseudomonas fluorescens strains. Lanes 1 and 7: molecular size marker $1 \mathrm{~kb}$ plus; 2: P. putida $\mathrm{Mm} 3$ strain from marine sponge; 3: P. fluorescens clinical strain; 4-6: P. putida clinical strains: B: dendrogram from computerassisted analysis of profiles shown in panel A. 
this may be not a reliable test to evaluate strains from the marine environment since these isolates encounter variations of temperature and salt concentration. The phenotypic test for metallo-beta-lactamase production was negative for Mm3. Genotyping by RAPD-PCR was performed and the DNA banding pattern of Mm3 was compared to that of clinical isolates. Fingerprint profiles and the respective dendrogram from a computer-assisted analysis are shown in Fig. 2. Genotyping of the Pseudomonas strains generated 11-18 bands between 2002,000 bp. Mm3 presented bands compatible in number and pattern with Pseudomonas strains. The isolates tested revealed a similarity higher than $60 \%$. A similarity of approximately $76 \%$ was observed between $\mathrm{Mm} 3$ and one clinical strain ( $\mathrm{n}^{\mathrm{o}} 3$, Fig. 2B). A plasmid of about $4.0 \mathrm{~kb}$ was also found in Mm3. Interestingly, no plasmid was described for P. putida strains with completely sequenced genomes.

This paper is the first report on the production of antimicrobial substances by bacteria isolated from sponges, which are abundant on the coast of Rio de Janeiro. Here, we discovered a $P$. putida isolate from the sponge $M$. microsigmatosa that produces a powerful antimicrobial substance, active against multidrug-resistant bacteria. Our results contribute to the search for new antimicrobial agents, an important strategy in developing alternative therapies to treat infections caused by multidrugresistant bacteria.

\section{ACKNOWLEDGEMENTS}

To Dr. Edson Rondinelli and his team of the Instituto de Biofísica Carlos Chagas Filho, for partial 16S rRNA gene sequencing, and to Dr. Walter Oelemann, for their assistance in the preparation of this manuscript.

\section{REFERENCES}

Arakawa Y, Shibata N, Shibayama K, Kurokawa H, Yagi T, Fujiwara H, Goto M 2000. Convenient test for screening metallo-betalactamase-producing Gram-negative bacteria by using thiol compounds. J Clin Microbiol 38: 40-43.

Atlas RM, Parks LC, Brown AE 1995. Laboratory manual of experimental microbiology, Mosby-Year Book, St. Louis, 719 pp.

Blondel-Hill E, Henry DA, Speert DP 2007. Pseudomonas. In PR Murray, EJ Baron, JH Jorgensen, ML Landry, MA Pfaller, Manual of clinical microbiology, ASM press, Washington DC, p. 734-748.

CLSI - Clinical and Laboratory Standards Institute 2003. Performance standards for antimicrobial sensitivity testing, CLSI, Pennsylvania, p. 49.
Faulkner DJ, Harper MK, Haygood MG, Salomon CE, Schmidt EW 2000. Symbiotic bacteria in sponges: sources of bioactive substances. In N Fusetani, Drugs from the sea, Karger, Basel, p. 107-119.

Felsenstein J 1985. Confidence limits on phylogenies: an approach using the bootstrap. Evolution 39: 783-791.

Gerwick WH, Coates RC, Engene N, Gerwick L, Grindberg RV, Jones AC, Sorrels CM 2008. Giant marine cyanobacteria produce exciting potential pharmaceuticals. Microbe 3: 277-284.

Giambiagi-deMarval M, Mafra MA, Penido EGC, Bastos MCF 1990. Distinct groups of plasmids correlated with bacteriocin production in Staphylococcus aureus. J Gen Microbiol 136: 1591-1599.

Mahenthiralingam E, Campbell ME, Foster J, Lam JS, Speert DP 1996. Random amplified polymorphic DNA typing of Pseudomonas aeruginosa isolates recovered from patients with cystic fibrosis. J Clin Microbiol 34: 1129-1135.

Monteiro LC, Muricy G 2004. Patterns of sponge distribution in Cagarras Arquipelago, Rio de Janeiro, Brazil. J Mar Biol Ass UK 84: 681-687.

Müller WEG, Grebenjuk VA, Pennec GL, Schröder HC, Brümmer F, Hentschel U, Müller IM, Breter HJ 2004. Sustainable production of bioactive compounds by sponges - cell culture and gene cluster approach: a review. Mar Biotechnol 6: 105-117.

Nascimento JS, Abrantes J, Giambiagi-deMarval M, Bastos MCF 2004. Growth conditions required for bacteriocin production by strains of Staphylococcus aureus. World J Microbiol Biotechnol 20: 941-947.

Netz DJA, Bastos MCF, Sahl HG 2002. Mode of action of the antimicrobial peptide aureocin A53 from Staphylococcus aureus. Appl Environ Microbiol 68: 5274-5280.

Olson JB, Harmody DK, McCarthy PJ 2002. Alpha-proteobacteria cultivated from marine sponges display branching rod morphology. FEMS Microbiol Lett 211: 169-173.

Pellegrino FL, Casali N, Dos Santos KR, Nouér SA, Scheidegger EM, Riley LW, Moreira BM 2006. Pseudomonas aeruginosa epidemic strain carrying bla(SPM) metallo-beta-lactamase detected in Rio de Janeiro, Brazil. J Chemother 18: 151-156.

Rice LB 2006. Antimicrobial resistance in Gram-positive bacteria. Am J Infect Control 34 (Suppl. 1): S11-19.

Saitou N, Nei M 1987. The neighbor-joining method: a new method for constructing phylogenetic trees. Mol Biol Evol 4: 406-425.

Sambrook J, Fritsch EF, Maniatis T 2001. Molecular cloning: a laboratory manual, Vol. I, 2nd ed., Cold Spring Harbor, New York, $748 \mathrm{pp}$.

Siqueira JF, Rôças IN, De Uzeda M, Colombo AP, Santos KR 2002. J Med Microbiol 51: 1090-1096.

Tamura K, Dudley J, Nei M, Kumar S 2007. MEGA4: Molecular Evolutionary Genetics Analysis (MEGA) software version 4.0. Mol Biol Evol 24: 1596-1599. 